\title{
A Bibliometric Study on Articles Published in PubMed-indexed Prosthodontic Journals in the Year 2016
}

\author{
Basnet B B ${ }^{1 *}$, Gyawali R ${ }^{2}$, Allhaj $\mathrm{MN}^{3}$ \\ ${ }^{1}$ Assistant Professor, Department of Prosthodontics, CODS, BPKIHS, Dharan, Nepal. \\ ${ }^{2}$ Assistant Professor, Department of Orthodontics, CODS, BPKIHS, Dharan, Nepal. \\ ${ }^{3}$ Lecturer, Department of Prosthodontics, Faculty of Dentistry, Thamar University, Dhamar, Yemen.
}

\begin{abstract}
Introduction: Publication trends of Prosthodontic literature in the PubMed-indexed journals in the year 2016 was studied to assess the number of authors, country affiliation of principal author, international collaboration in authorship, type of studies, major field of study. The bibliometric study helps to determine the scientific growth and development.

Aims and objectives: The aim of this study was to explore the prosthodontics literature in PubMedindexed journals in the year 2016.

Materials and methods: All the published articles excluding the book review, letter to editor, panel discussion etc were assessed and the data regarding the number of authors, affiliation of principal author, international collaboration in authorship, type of studies, number of references were entered into Microsoft Excel and analyzed for demographic findings.

Results: 645 articles satisfied the inclusion criteria. Principal authors from Asian countries contributed for major bulk of the studies (51\%). Major emphasis of study is attracted to dental materials, CADCAM, zirconia, cements (categorized under "other" in this study). The in-vitro studies were more prevalent in the year 2016 (>35\%). Though international collaboration has been found in many articles, single authorship has decreased (4.81\%).

Conclusion: The collaboration amongst authors is increased but international collaboration is still less and the newer topics of interest are being studied rather than conventional prosthetic sciences.
\end{abstract}

Key words: Prosthodontics journals, International collaboration, Principal authorship, PubMedindexed journals

\section{Introduction}

66 lingering sense of uncertainty about the threatens to undermine my optimism about the future." - Zarb GA ${ }^{1}$

Research activities are representation of the development of a specialty and the publication of these works will calibrate the level of growth and development of that particular specialty. There have been considerable examinations

\section{*Corresponding Author}

Dr. Bishal Babu Basnet, Assistant Professor, Department of Prosthodontics; CODS, B P Koirala Institute of Health Sciences,Dharan, Nepal

E-mail:bishalbpkihs@yahoo.com into the research trends such as types of articles, area of research fields, topics of interests and emerging trends in many dental spcialities..$^{2-6}$

Many authors have contributed by analytically reviewing the past prosthodontic literature. In a rigorous study done over three representative journals of Prosthodontics viz. International journal of Prosthodontics (IJP), Journal of Prosthetic Dentistry (JPD) and Journal of Prosthodontics(JP); a group of authors studied 998 articles published in the years 1998, 2003 and 2008. They publicized their important findings in the same journals in the year $2010,{ }^{7}$ $2011^{8}$ and $2012,{ }^{9}$ however, search was limited to three journals from Prosthodontics. The 
prosthodontics literature has been widened to encompass many journals in dental fields. Therefore there is a need to assess all available resources to examine the pattern and trends of prosthodontic literature.

It is noticeably seen that prosthodontic literature has been boosted by the theses of Master's degree and some authors question about its importance in producing higher degree of knowledge. ${ }^{10}$ The globalization has huge impact on everything we do in modern days, publication of literature cannot be an exception. Bibliometric study will help to assess the trends and pattern of publication and determine the productivity of literature. It is expected to have shared knowledge and skills in the field of prosthodontics for the betterment of society and discipline itself. The aim of this study is to explore and analyze the trends of publication in the PubMed-indexed prosthodontic journals in the year 2016 .

\section{Materials and methods}

The year 2016 was chosen, as it was a completed year while the research design of this study was incepted. Via NLM library, currently publishing PubMed-indexed prosthodontic journals were selected which were exclusively publishing the articles in Prosthodontics. The final journals to be included in the study were International journal of Prosthodontics (IJP), Journal of Prosthetic Dentistry(JPD), Journal of Prosthodontics(JP), Journal of Indian Prosthodontic Society(JIPS), Journal of Advanced Prosthodontics(JAP) and Journal of Prosthodontic Research(JPR).

The articles such as original research, case reports, review, systematic review, technical innovation or tips were considered for the study excluding the editorial, guest editorial, letter to editor, corrigendum, panel directives, book reviews, etc.

For selected articles, full-texts were studied for gaining the information such as number of authors, affiliation of principal author, international collaboration in authorship,type of study, major topic of study and number of references used in the study.

The types of study was classified as observational and experimental as suggested by Grimes and Schulz. ${ }^{11}$ The observational study would be descriptive, case-control, cohort and crosssectional. Experimental study can encompass randomized or non-randomized controlled trial. Based on prespecified scientific criteria for selecting the published literature, review articles would be either narrative review or systematic review (with or without meta-analysis). ${ }^{12}$

Current study took basic types for ease of comparison and critical appraisal. The types of studies described in current study are cohort, case-control, retrospective study, cross-sectional study, non randomized clinical trials, randomized clinical trials, in-vitro study, systematic review (with or without metaanalysis), case reports and technical tips or innovations.

The preliminary screening was done by BBB and $\mathrm{RG}$ and when dispute existed in classifying the articles, MNA was sought.

The major fields of prosthodontics are conventionally considered such as complete dentures, removable partial dentures, fixed partial denture and crowns, dental implant and maxillofacial prosthesis. The fields not categorized under these broad headings were grouped under "other" in our study, which included dental materials, ceramics, resins, dental education, knowledge, attitude, translational studies, cost analyses, CAD-CAM etc. The categorization was done based on the content of the article by BBB and the doubts were sorted out by consulting RG and MNJ.

The data were entered into Microsoft excel and analysis was performed. 


\section{Results}

PubMed-indexed six prosthodontic journals were screened for the initiation of this study. Total 42 issues were published in these journals in the year 2016. Among them JP published "Glossary of Digital Dental Terms" in one of its issues, therefore that issue was excluded from the study.

A total of 645 articles satisfied the inclusion criteria. JPD outnumbered other journals with 270 articles followed by IJP (100) and JP (98).

Number of authors ranged from 1 to 12 with overall mean number of authors per article being4.28 [Table 1]. The mean number of authors per article was found to be almost similar with highest for JP (4.83) and lowest for JIPS (3.82).

Maximum number of principal authors were affiliated to USA (91), India (87), Brazil (65) and Korea (71). Asia accounted for highest contribution in the year 2016 with $51 \%$ of the publication (fig. 1).

Table 1: Number of authors in each journal
Table 2 shows the distribution of principal authors by journal and country of affiliation and also gives the number of articles discussing various subject areas in each journal. While taking the country of affiliation 8 articles had ambiguous information because of dual affiliation. The country with permanent post, or research site or mentioned at the first was taken in account in these articles.

The most prevalent type of subject or topic was incorporated in "other" field with $36.43 \%$ articles from this category (Table 2). This was followed by implant $(30.54 \%)$ and least were drawn from RPD (2.95\%).

In taking the number of references, mean number of references per article was 27.21 with range (0-337).

Higher percentage of international collaboration was seen in JP, IJP and JPD (about 20\%) and lower in JAP and JIPS [fig. 2]. The in-vitro study was on top of the list in prosthodontic literature in the year 2016 [fig. 3] while systematic reviews and randomized clinical trials were less in number.

\begin{tabular}{|c|c|c|c|c|c|c|c|}
\hline No of authors & IJP & JAP & JIPS & JP & JPD & JPR & Grand Total \\
\hline 1 & 4 & 2 & 5 & 6 & 14 & 2 & 33 \\
\hline 2 & 13 & 10 & 7 & 7 & 38 & 7 & 82 \\
\hline 3 & 17 & 10 & 18 & 14 & 41 & 5 & 105 \\
\hline 4 & 14 & 15 & 21 & 20 & 84 & 5 & 159 \\
\hline 5 & 25 & 15 & 9 & 17 & 40 & 7 & 113 \\
\hline 6 & 19 & 7 & 9 & 13 & 32 & 6 & 86 \\
\hline 7 & 6 & 2 & 1 & 10 & 9 & 2 & 30 \\
\hline 9 & 1 & 3 & 1 & 7 & 5 & 6 & 22 \\
\hline 10 & 1 & & & 1 & 4 & 2 & 8 \\
\hline 11 & & & & 3 & 1 & & 2 \\
\hline 12 & $\mathbf{1 0 0}$ & $\mathbf{6 4}$ & $\mathbf{7 1}$ & $\mathbf{9 8}$ & $\mathbf{2 7 0}$ & $\mathbf{4 2}$ & $\mathbf{6 4 5}$ \\
\hline Grand Total & 4.37 & 4.17 & 3.82 & 4.83 & 4.12 & 4.81 & 4.28 \\
\hline $\begin{array}{c}\text { Mean number } \\
\text { of authors }\end{array}$ & 4 & & & & & \\
\hline
\end{tabular}

Note: IJP - International Journal of Prosthodontics, JAP -Journal of Advanced Prosthodontics, JIPS - Journal of Indian Prosthodontic Society, JP - Journal of Prosthodontics,JPD - Journal of Prosthetic Dentistry, JPR - Journal of Prosthodontic Research. 
Table 2: The country of affiliation of principal author in different journals and subject of concern of the articles

\begin{tabular}{|c|c|c|c|c|c|c|c|}
\hline Country & IJP & JAP & JIPS & JP & JPD & JPR & Grand total \\
\hline Africa & 1 & 2 & 2 & 2 & 9 & - & 16 \\
\hline Egypt & - & 2 & 2 & 1 & 6 & - & 11 \\
\hline Nigeria & & - & - & - & 1 & - & 1 \\
\hline South Africa & 1 & - & - & 1 & 2 & - & 4 \\
\hline Asia & 33 & 54 & 66 & 36 & 107 & 33 & 329 \\
\hline China & 8 & & & 3 & 18 & 2 & 31 \\
\hline Hongkong & 1 & - & - & - & - & 1 & 2 \\
\hline India & 1 & 1 & 61 & 12 & 11 & 1 & 87 \\
\hline Iran & 1 & 3 & - & 2 & 2 & & 8 \\
\hline Iraq & - & - & - & - & 1 & & 1 \\
\hline Israel & 1 & - & - & - & 3 & & 4 \\
\hline Japan & 7 & 2 & - & 4 & 6 & 21 & 40 \\
\hline Jordan & - & - & - & 1 & & & 1 \\
\hline Korea & 9 & 32 & - & 1 & 26 & 3 & 71 \\
\hline Kuwait & - & - & - & - & 1 & & 1 \\
\hline Lebanon & - & - & - & - & 1 & & 1 \\
\hline Malaysia & 1 & 1 & 1 & - & & & 3 \\
\hline Nepal & - & - & - & - & 1 & & 1 \\
\hline Pakistan & - & - & - & - & & 1 & 1 \\
\hline Saudi Arabia & 2 & 1 & 1 & 3 & 12 & 1 & 20 \\
\hline Singapore & - & - & - & - & 1 & & 1 \\
\hline Syria & - & - & 2 & 1 & 1 & & 4 \\
\hline Taiwan & - & - & - & - & 4 & & 4 \\
\hline Thailand & - & 1 & - & - & 1 & & 2 \\
\hline Turkey & 2 & 13 & 1 & 9 & 18 & 3 & 46 \\
\hline Europe Total & 45 & 7 & 1 & 14 & 54 & 5 & 126 \\
\hline Austria & 2 & 1 & & & & & 3 \\
\hline Belgium & & 1 & & & & & 1 \\
\hline Croatia & 1 & & & & 1 & & 2 \\
\hline Denmark & 2 & & & & & & 2 \\
\hline Finland & & & & & 5 & & 5 \\
\hline France & 2 & & & & 3 & & 5 \\
\hline Germany & 12 & 1 & & 1 & 8 & 3 & 25 \\
\hline Greece & 3 & & & 2 & 6 & & 11 \\
\hline Italy & 3 & & & 5 & 5 & & 13 \\
\hline Malta & 1 & & & & & & 1 \\
\hline Netherlands & 6 & & & & 3 & & 9 \\
\hline Norway & & & & & 1 & & 1 \\
\hline Poland & & & & & 1 & & 1 \\
\hline Portugal & & 1 & & 1 & 1 & & 3 \\
\hline Romania & & & & & 1 & & 1 \\
\hline Serbia & 1 & & & & & & 1 \\
\hline
\end{tabular}




\begin{tabular}{|c|c|c|c|c|c|c|c|}
\hline Slovenia & 1 & & & & & & 1 \\
\hline Spain & 6 & 3 & & 1 & 10 & & 20 \\
\hline Sweden & 4 & & 1 & 1 & & & 6 \\
\hline Switzerland & & & & 1 & 4 & 1 & 6 \\
\hline UK & 1 & & & 2 & 5 & 1 & 9 \\
\hline $\begin{array}{l}\text { North America } \\
\text { Total }\end{array}$ & 4 & & 1 & 29 & 61 & 2 & 97 \\
\hline Canada & 2 & & & & 3 & & 5 \\
\hline Mexico & & & & & 1 & & 1 \\
\hline USA & 2 & & 1 & 29 & 57 & 2 & 91 \\
\hline Ocenia Total & 5 & & & 1 & 4 & & 10 \\
\hline Australia & 4 & & & 1 & 2 & & 7 \\
\hline New Zealand & 1 & & & & 2 & & 3 \\
\hline $\begin{array}{l}\text { South America } \\
\text { Total }\end{array}$ & 12 & 1 & 1 & 16 & 35 & 2 & 67 \\
\hline Brazil & 12 & 1 & 1 & 15 & 34 & 2 & 65 \\
\hline Chile & & & & 1 & & & 1 \\
\hline Ecuador & & & & & 1 & & 1 \\
\hline \multicolumn{8}{|c|}{ Subject of concern } \\
\hline $\mathrm{CD}$ & 7 & 5 & 8 & 12 & 19 & 5 & 56 \\
\hline FPD & 16 & 6 & 12 & 11 & 42 & 3 & 90 \\
\hline Implant & 47 & 20 & 18 & 23 & 75 & 15 & 198 \\
\hline MFP & 7 & 3 & 9 & 11 & 16 & 2 & 48 \\
\hline Other & 19 & 29 & 21 & 35 & 113 & 17 & 234 \\
\hline RPD & 4 & 1 & 3 & 6 & 5 & & 19 \\
\hline Grand Total & 100 & 64 & 71 & 98 & 270 & 42 & 645 \\
\hline
\end{tabular}

\#CD - Complete denture, FPD - Fixed partial denture, MFP - Maxillofacial prosthesis, RPD - Removable partial denture.

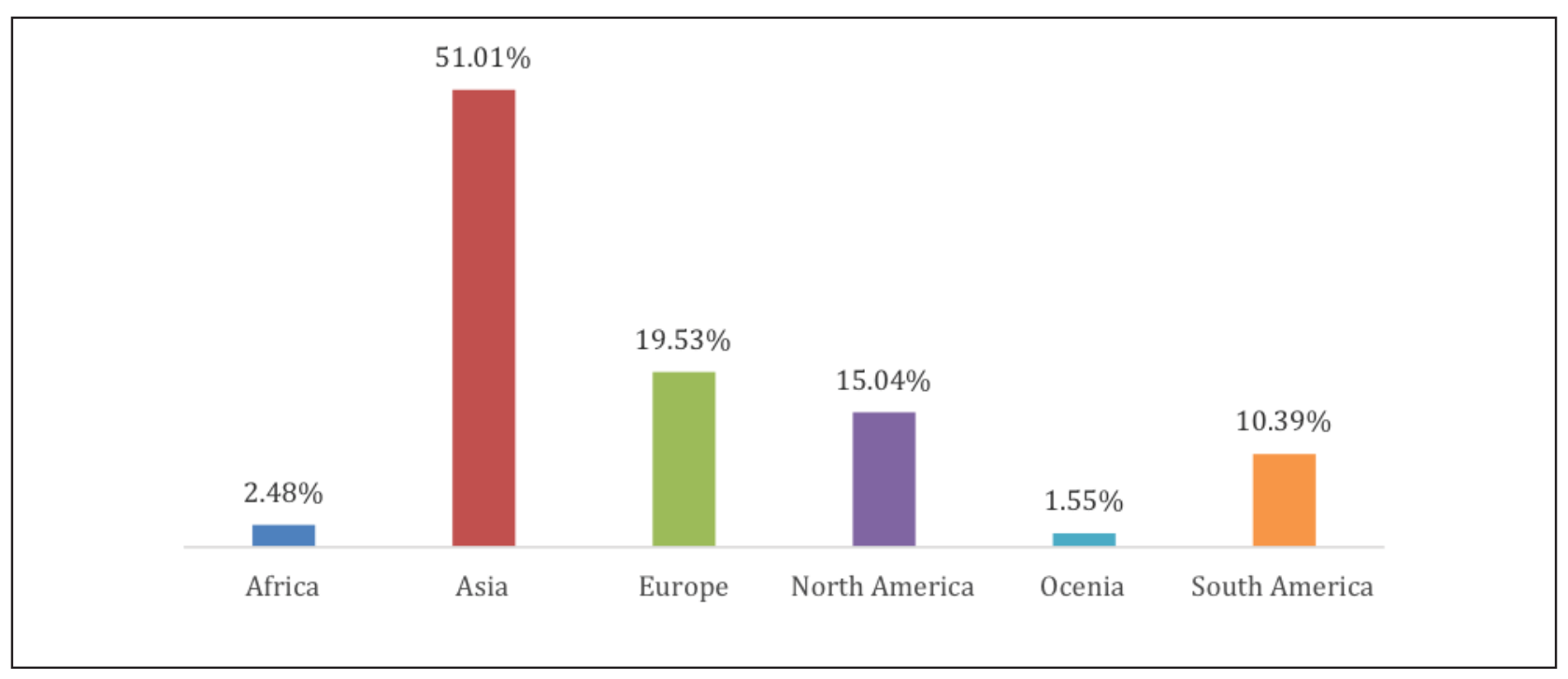

Figure 1: Principal author affiliation by continents 


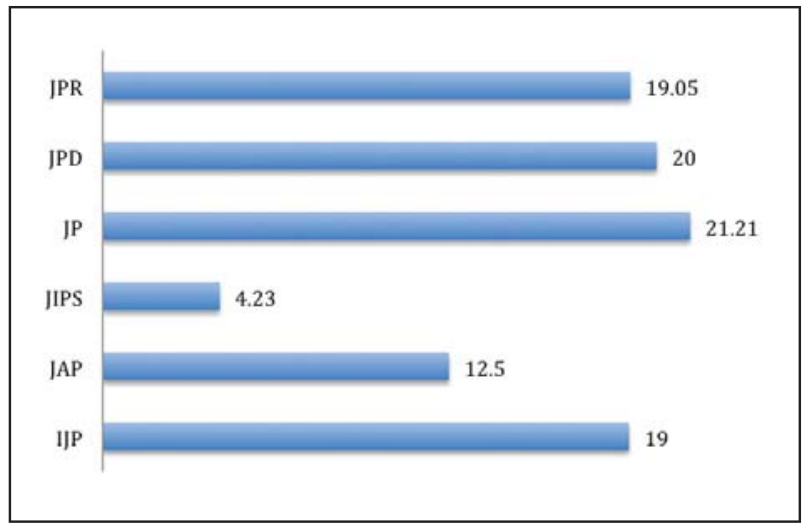

Figure 2: Percentage of international collaboration in authorship in each journal

\section{Discussion}

The aim of the current study was to explore prosthodontic journals for article type, topic of study, number of authors and international collaboration in authorship in the PubMedindexed prosthodontic journals in the year 2016. Since more journals were published from developed countries, developing countries lack the attention in the publication. Simple counts of the number of publications, however couldn't reflect the research productivity. ${ }^{13}$ In contrast to the previous tradition, current study included affiliation of all authors to compare the articles with international collaboration. International collaboration was found to be disproportionate in JIPS with a ratio as low as 1:21, conversely JP had higher ratio of 1:3.4. Other journals published from USA and Japan (IJP, JPD and JPR) had almost same ratio of 1:4 (international collaboration present to absent ratio).Collaborative work is believed to produce superior quality of research and often more citations are drawn towards such articles. ${ }^{14}$ However, in developing countries the international collaboration was reported to be minimal inother specialty such as orthodontics. ${ }^{4}$ Over the period of ten years, prosthodontics had significant number of articles published form Asia, Europe and North America (92.0\%), the increment being considerable while comparing the publication between 2008 and $1998 .^{9}$ This

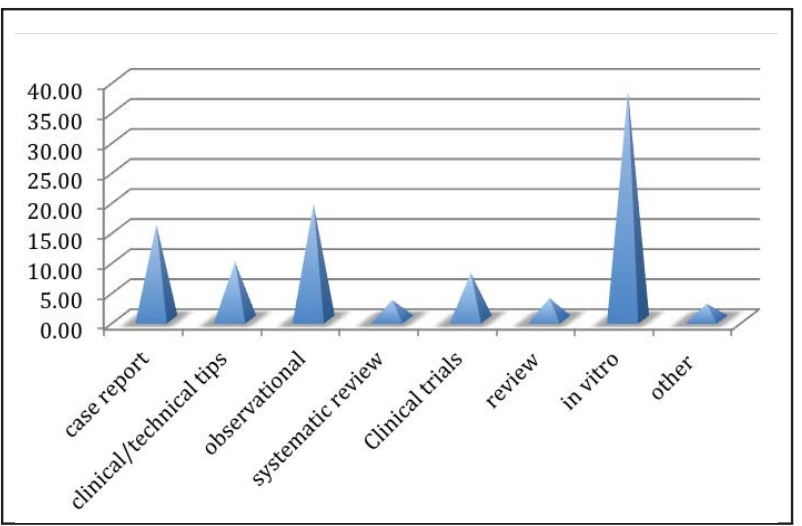

Figure 3: Type of articles in all journals

holds true in current study as more number of articles originated from principal authors from Asia (51\%) and Europe (20\%). Among Asian countries; India, Japan, Turkey and Korea had higher number of principal authors. Similarly, Germany and Spain from Europe and USA from North America had more principal authorship. This was found to be in contrast to Thornton et al. if we compared the year 2008 as there was $38.2 \%$ authorship from North America and about $25.7 \%$ each from Asia and Europe. ${ }^{9}$ It was due to the fact that only three journals (JP, JPD and IJP) were considered in their study.

The scenario in current study possibly has editorial biases in literature regarding the publication. In JIPS, almost $70.11 \%$ articles $(n=87)$ originated from India (publishing country; India). Similar findings were attributed to JPR, with $52.5 \%(n=40)$ articles from principal author of Japan (publishing country; Japan). In JAP, 45.07\% $(\mathrm{n}=71)$ articles were published with principal authorship of Korea (publishing country; Korea). The potential biases may play role in such kind of publications. ${ }^{15}$ This was not so apparent in JP, JPD or IJP with predilection over one particular country. However, publication from principal authorship from USA was $62.63 \%(n=91)$ in JPD and $31.87 \%$ $(\mathrm{n}=91)$ in JP. From Brazil, 52.31\% $(\mathrm{n}=65)$ were published in JPD. 
In modern day prosthodontics, more research, case reports or reviews were dragged towards digital dentistry, technologies, CAD-CAM and material sciences. ${ }^{16}$ This was true in the current study as more articles (36.43\%) were from "other" category [table 2], which included these types of topics or fields. Implants accounted for more articles (30.54\%) than the conventional prosthetic sections (CD, FPD, MFP or RPD). An increase in original research and collaboration with more research focused to clinical care, educative works, public health and dental materials was reported by Lee et al. ${ }^{8}$ The higher degree of works in the form of systematic review and meta-analysis was scant in this year's overall publication [Fig. 3]. Invitro study, case reports and observational study were reported to be in adequacy.

The proportion of single authorship had declined in modern day-publication in which international collaboration is not applicable. Yuan et al. found that it was $17 \%$ in 1998 and $5 \%$ in $2008 .^{7}$ In agreement with their findings of the year 2008, single authorship in current study is very low (4.81\%). Single authorship was an outdated practice in other fields as well $(8.73 \%$ in orthodontic journals form South Asia region). ${ }^{4}$

Greater international collaboration is the need of time. Wiens points out the need of change in thinking of prosthodontists not to remain solely as the prosthetic dentists but rise to the level of prosthodontic research scientists. ${ }^{17}$ He suggests the formation of 'Research Intermedicus for Prosthodontic Exchange' (RIPE) to promote prosthodontic science and research mentorship worldwide.

\section{Conclusions}

Within the limitations of this study following conclusions were drawn:-

The topics of interest in research, review and case reports have been in the phase of swift transmission from conventional model to newer trends. International collaboration, although has been growing in the developed countries, found to be still less in developing countries. More number of authors are involved in generating an article in all the PubMed-indexed journals. Potential biases of publication still exist in some journals giving more priority towards the origin from same country.

\section{Conflict of interest: None}

\section{References}

1. Zarb GA. On prosthodontic research: old baggage, new directions. Int $\mathrm{J}$ Prosthodont 2003;16(suppl.):7-10.

2. Sukotjo C, Yuan JCC, Bordage G. A content analysis of dental education research as reported in two journals. J Dent Educ 2010;74:1106-12.

3. Birkhahn RH, Van Deusen SK, Okpara OI, Datillo PA, Briggs WM, Gaeta TJ. Funding and publishing trends in original research by emerging medicine investigators over the past decade. Acad Emerg Med 2006;13:95-101.

4. Gyawali R, Pokhrel PR, Giri J. Demography of publications in South Asian orthodontic journals. J Indian Orthod Soc 2017;51:87-91.

5. Eghal MJ, Ardakani ND, Asgary S. A scientometric study of PubMed-indexed endodontic articles: a comparison between Iran and other regional countries. Iranian Endodontic Journal 2012;7:56-9.

6. Valkova V, Maheen CU, Pommer B, RauschFan X, Seeman R. Hot topics in clinical oral implants research: recent trends in literature coverage. Dent J 2016;4:1-10.

7. Yuan JCC, Lee DJ, Knoernschild KL, Campbell SD, Sukotjo C. Authorship characteristics in prosthodontic literature: proliferation analysis following a 10-year observation. J Prosthet Dent 2010;104:158-64.

8. Lee DJ, Yuan JCC, Knoernshild KL, Campbell SD, Sukotjo C. Research in Prosthodontics: a 10-year observation of trends in topics, collaboration and funding. Int $\mathrm{J}$ Prosthodont 2011;24:473-8.

9. Thornton K, Lee DJ, Yuan JCC, Knoernschild KL, Campbell SD, Sukotjo C. An analysis Journal of Nepalese Prosthodontic Society (JNPS) 
of prosthodontic research productivity: geographic, economic and collaborative perspective. J Prosthodont 2012;21:73-8.

10. Stohler CS. Prosthodontic research: breaking traditional barriers. J Can Dent Assoc 2005;71:332.

11. Grimes DA, Schulz KF. An overview of clinical research: The istiplay of the land. Lancet 2002;359:57-61.

12. O'Connor D, Green S, Higgins JP. Defining the review question istepand developing criteria for including studies. In: Higgins JP, Green $\mathrm{S}$, editors. Cochrane Handbook of Systematic Reviews of Interventions. Ch. 5. Chichester, UK: John Wiley and Sons; 2008. is[ep?
13. Hefler L, Tempfer C, Kainz C. Geography of biomedical publications in the European Union, 1990-98. The Lancet 1999;353:1856.

14. Figgs WD, Dunn L, Liewehr D, Steinberg SM, Thurman PW, Barett JC et al. Scientific collaboration results in higher citation rates of published articles. Pharmacotherapy 2006;26:759-67.

15. Mateias-Guiu J, Garcia-Ramos R. Editorial bias in scientific publications. Neurologia 2011;26(1):1-5.

16. Baba K. Paradigm shifts in prosthodontics. J Prosthodnt Res 2014;58:1-2.

17. Wiens JP. Leadership, stewardship and prosthodontics' future. Int J Prosthodont 2007, 20:456-8. 